\title{
Pre-clinical studies of bone regeneration with human bone marrow stromal cells and biphasic calcium phosphate
}

\author{
Meadhbh Á Brennan', Audrey Renaud', Jérôme Amiaud', Markus T Rojewski ${ }^{2}$ Hubert Schrezenmeier², \\ Dominique Heymann ${ }^{1}$, Valerie Trichet $^{1}$ and Pierre Layrolle ${ }^{1 *}$
}

\begin{abstract}
Introduction: Repair of large bone defects remains a significant clinical challenge. Bone marrow stromal cells (BMSCs), a subset of which is known as bone marrow-derived mesenchymal stem cells, show therapeutic potential for bone regeneration. However, their isolation, expansion and implantation will need to be conducted under good manufacturing practices (GMP) at separate locations. An investigation which mimics this clinical scenario where large bone defects shall be regenerated is required before clinical trials can be initiated.

Methods: Seven batches of 100 million human ex-vivo expanded BMSCs from five donors were transported fresh in syringes from a GMP facility in Germany to France. BMSCs were mixed with biphasic calcium phosphate (BCP) biomaterial prior to subcutaneous implantation in nude mice. The capacity of BMSCs in unison with BCP to regenerate critical sized cranial bone defects was also evaluated. BMSCs expressing luciferase were used to assess the viability and bio-distribution of implanted cells. In situ hybridization, using the human-specific repetitive Alu sequence, was performed for the identification of human cells in explants.
\end{abstract}

Results: Eight weeks after implantation of BMSCs, mineralized bone containing mature bone marrow territories was formed in ectopic sites and in calvaria defects. Significant loss of cell viability was observed by bioluminescence imaging and only 1.5 percent of the initial number of transplanted cells remained after 37 days. After eight weeks, while explants were comprised primarily of host cells, there were also human cells attached along the periphery of $\mathrm{BCP}$ and embedded in osteocyte lacunae dispersed throughout the newly formed bone matrix.

Conclusions: This study demonstrates the safety and efficacy of BMSC/BCP combinations and provides crucial information for the implementation of BMSC therapy for bone regeneration.

\section{Introduction}

Successful repair of bone defects caused by trauma, cancer or metabolic diseases remains a significant clinical challenge for reconstructive surgeons. Bone is the most frequently transplanted tissue, with 2.2 million bone replacement procedures conducted globally each year [1]. Autologous bone transplantation is limited by the quantity and quality of grafted bone and can lead to complications at the second surgical site, while allogenic bone grafts pose the risk of disease transfer and immunologic rejection.

\footnotetext{
* Correspondence: pierre.layrolle@inserm.fr

'INSERM, UMR957, Laboratory of the Pathophysiology of Bone Resorption, Faculty of Medicine, 1 Rue Gaston Veil, 44035, University of Nantes, Nantes, France Full list of author information is available at the end of the article
}

Consequently, there are considerable incentives for developing alternative solutions for bone regeneration.

Significant opportunities exist for tissue engineering strategies in orthopedic and maxillofacial surgery. Synthetic biomaterial scaffolds in association with bone marrow stromal cells (BMSCs), a subset of which is known as bone marrow-derived mesenchymal stem cells, could overcome the limitations of biological bone grafts. BMSCs are multipotent progenitor cells, capable of differentiating into osteoblasts, chondrocytes and adipocytes [2], and are therefore considered promising for tissue engineering applications. Human BMSCs can be isolated from a small volume of bone marrow aspiration under local anesthesia. However, due to the diminutive number of BMSCs in bone marrow (0.001 to $0.01 \%$ of bone marrow mononuclear cells 
(BM-MNCs) ) [3], expansion ex vivo is necessary to obtain clinically transplantable doses. Since BMSCs are deemed an advanced therapy medicinal product by the European Commission [4], they must be produced in accordance with good manufacturing practice (GMP). Safe, robust and GMP-compliant protocols for large-scale isolation and expansion of BMSCs, which avoid animal products such as fetal calf serum by using human platelet lysate (PL), have been developed [5-8]. Published data identified transforming growth factor beta-1, vascular endothelial growth factor, platelet-derived growth factor, fibroblast growth factor and epidermal growth factor among effectors of PL activity [5,9]. Furthermore, it has been demonstrated previously that $\mathrm{PL}$ is a safe alternative to fetal calf serum for culturing human BMSCs and that it favors both osteoblastic differentiation and bone tissue formation $[6,10]$.

The capacity of BMSCs for bone repair has been studied in vivo with promising results [11-13]. However, for clinical relevance it is clear that the isolation, expansion and implantation of cells will need to be conducted at separate facilities, often with considerable distances between the cell production site and the surgical room. Cryopreserved BMSCs maintain their bone formation capabilities [14]. However, the transportation of frozen cells directly to the operating theater is not feasible because of the time required for cells to recover function after thawing [15] and the potential adverse effects of the cryoprotectants [16]. Veronesi and colleagues have recently determined that when freshly harvested BMSCs are suspended in a saline/ human serum albumin (HSA) solution, cell viability is maintained and bone formation in small-scale implants can be achieved [17]. Nevertheless, there is a need to evaluate the bone regeneration of BMSCs that have undergone large-scale GMP expansion and transportation to a separate facility in clinically relevant numbers and time frames.

Determining the cell dose of BMSCs required for adequate bone and hematopoiesis formation is of immense interest for bone tissue engineering. While it might be expected that higher numbers of cells would lead to increased bone formation, Mankani and colleagues have demonstrated a threshold beyond which more transplanted cells do not lead to more bone formation [12].

Adequate biomaterial scaffolds are required for the transplantation of BMSCs targeted at repairing osseous defects. BMSCs combined with porous calcium phosphate ceramics, namely hydroxyapatite/beta-tricalcium phosphate, have been shown to induce bone formation in the subcutis of nude mice $[12,18,19]$ and in femoral defects in rats [20]. Biphasic calcium phosphate (BCP) biomaterials are widely used for bone augmentation, for filling bone defects in combination with autologous bone marrow, or for supplementing autologous bone grafts.

A further requirement for an advanced therapy medicinal product prior to entering clinical trials is the demonstration of the bio-distribution of the transplanted BMSCs. There are conflicting observations as to the fate of BMSCs transplanted within biomaterial scaffolds and whether the newly formed bone is of host or donor cell origin. Evidence for donor BMSCs being involved in bone regeneration comes from studies that demonstrate osteoblasts and osteocytes of donor origin within newly formed bone $[13,21,22]$. Less donor cells were present in later harvest transplants than at earlier time points, however [22]. Conversely, Tasso and colleagues demonstrated that donor BMSCs disappeared from the scaffold after the second week of implantation and the newly formed bone was entirely of host origin [23]. Studies assessing implanted cell survival have shown substantial death of implanted donor cells [24,25]. One study revealed that $50 \%$ of initial donor BMSCs remained 48 hours after implantation, while 5\% remained after 8 weeks [24]. Another study showed that less than $1 \%$ was detectable after 30 days [25]. An investigation of the real-time metabolic activity of transplanted cells and the cell origin of bone formation would therefore shed light on whether bone is formed directly by donor cells, or whether a paracrine effect induces a host stromal cell response.

The first objective of this study was to determine the optimal cell dosage required for bone formation before scaling up to relevant clinical numbers of BMSCs. The study sought to transport freshly produced BMSCs from a GMP facility, where they were isolated and expanded, to another site where they were mixed with biomaterial and implanted, mimicking as much as possible the clinical scenario where large bone defects of 5 to $10 \mathrm{~cm}^{3}$ shall be regenerated. The objectives were to quantify the degree of ectopic bone and hematopoietic compartment formation, as well as bone regeneration in critical-sized defects in nude mice. A final premise of this study was to explore the cell fate and biological activity of transplanted human BMSCs and to determine whether newly formed bone was of host or donor origin.

\section{Methods}

\section{Biomaterial}

BCP, a ceramic composed of hydroxyapatite/beta-tricalcium phosphate in a ratio of $20 / 80$ by weight, was used because this composition has previously demonstrated bone induction [19]. BCP granules, ranging in size from 1 to $2 \mathrm{~mm}$, were supplied by Biomatlante (Vigneux de Bretagne, France) under the brand name MBCP+. MBCP + is CE and US Food and Drug Administration 510(k) approved as a synthetic bone substitute. BCP discs, $7 \mathrm{~mm}$ in diameter and $2 \mathrm{~mm}$ in thickness, were used for calvaria regeneration. The overall porosity (\%vol) was $75 \pm 5 \%$, with a pore size distribution of $70 \%$ ( 0 to $10 \mu \mathrm{m}$ ), 20\% (10 to $100 \mu \mathrm{m})$ and $10 \%(100$ to $300 \mu \mathrm{m})$. The BCP biomaterials 
were supplied in double-sealed packaging and gammasterilized at $25 \mathrm{kGray}$.

\section{Isolation, expansion and characterization of clinical batches of GMP-grade BMSCs}

Bone marrow aspirates were obtained from the iliac crest, by standard puncture and aspiration, of healthy human donors (21 to 26 years old) after receiving informed consent according to the Declaration of Helsinki. The project was approved by the Ethical Committee of Ulm University. A maximum of $37 \mathrm{ml}$ bone marrow was aspirated using up to four $20 \mathrm{ml}$ Omnifix syringes (B. Braun, Melsungen, Germany) and transplant aspiration needles (Somatex, Teltow, Germany). Each syringe was prefilled with 1,000 IU heparin in $2 \mathrm{ml} \mathrm{NaCl}$ (B. Braun). BMSCs used in this study are of GMP grade and were expanded according to previously published protocols [6]. In brief, BMSCs were isolated from heparinized bone marrow aspirates by seeding 50,000 white blood cells $/ \mathrm{cm}^{2}$ on two-chamber CellStacks (Corning/VWR, Ulm, Germany) in alpha minimum essential medium (Lonza, Basel, Switzerland) supplemented with 5\% GMP-grade human platelet lysate (IKT, Ulm, Germany) in order to avoid animal products [5]. Cells were cultured for 10 or 14 days with medium exchange twice per week. Cells were detached and reseeded at a density of $4,000 \mathrm{BMSCs} / \mathrm{cm}^{2}$ on two-chamber CellStacks in alpha minimum essential medium supplemented with $8 \%$ PL for a further 5 or 7 days. A production license for this protocol has been granted from the regional government (Regierungspräsidium Tübingen, Germany; production and import license: DE_BW_01_ MIA_2013_0040/DE_BW_01_IKT Ulm). To assess the quality of the aspirates, measures such as colony-forming units (CFUs-F), BM-MNC content and doubling times were measured. For phenotypic characterization, flow cytometry was performed as described previously [5,6]. Fluorescent intensities of 50,000 to 100,000 BMSCs were acquired. Briefly, BMSCs were stained for 15 minutes in $100 \mu \mathrm{l}$ phosphate-buffered saline using the following combinations of antibodies: IgG-FITC (clone X40), IgG-PE (clone X40), IgG-PerCP (clone X40); CD90-FITC (clone 5E10), CD34-PE (clone 8G12), CD45-PerCP (clone 2D1); CD105-FITC (clone SN6), CD73-PE (clone AD2), CD3PerCP (clone SK7); and HLA-DR,DQ,DP-FITC (clone Tü39), HLA-A,B,C-PE (clone G46-2.6). All antibodies were sourced from Becton Dickinson (Heidelberg, Germany), except CD105 that was from AbDSerotec (Puchheim, Germany). After washing with phosphatebuffered saline, cells were analyzed using a BD FACScan (BD Biosciences, Heidelberg, Germany).

Differentiation capacity of expanded BMSCs was performed as described previously [5,6]. Briefly, BMSCs differentiation was induced using adipogenic differentiation medium from Lonza or chondrogenic or osteogenic differentiation media from Miltenyi (Bergisch Gladbach, Germany) according to the manufacturers' instructions. For detection of adipogenic differentiation, cells were stained with Oil Red O solution in 2-propanol, diluted to 60\% using deionized water. Chondrogenic differentiation was detected by Alcian Blue staining, while mineralization was detected by Alizarin red staining.

\section{Cell numbers required for bone formation}

Prior to the transportation of large batches of fresh BMSCs for bone repair, it was necessary to quantify the optimal dose of cells for bone formation in proportionally lower numbers. Different quantities of BMSCs in passage 2 from three different human donors were mixed with $50 \mathrm{mg}$ BCP particles and allowed to attach for 1 hour prior to subcutaneous implantation in nude mice. Number of cells per implant and number of implants per group were as follows: 0 cells, $n=5 ; 0.1 \times 10^{6}$ cells, $n=9 ; 2 \times 10^{6}$ cells, $n=9$; and $4 \times 10^{6}$ cells, $n=9$.

\section{Transportation of fresh bone marrow stromal cells}

Cells were harvested and washed, and $100 \times 10^{6}$ passage 1 BMSCs from each of the five donors were suspended in $7 \mathrm{ml}$ saline solution supplemented with $4 \%$, $5 \%$ or $20 \%$ HSA solution (CSL Behring, Hattersheim am Main, Germany) in a sterile luer lock $20 \mathrm{ml}$ syringe (B. Braun). Cells were transported within 24 hours from Ulm (BadenWurttemberg, Germany) to Nantes (Pays de la Loire, France) at $20^{\circ} \mathrm{C}$ via TNT Express overnight courier. Upon arrival, cell viability was confirmed using the trypan blue exclusion method. Each syringe containing BMSCs was connected to a syringe containing $5 \mathrm{~cm}^{3}$ BCP particles (2.5 g) using a double luer lock. Cells were allowed to attach to the BCP particles for 1 hour, prior to implantation in nude mice. Cell attachment was confirmed by methylene blue staining.

\section{Bone marrow stromal cell/biomaterial implantation in the subcutis and calvaria of nude mice}

All animal experiments were performed according to Directive 2010/63/UE and after approval of protocols from the local ethical committee (CEEA, Pays-de-la-Loire, France). Immunocompromised female mice (RjOrl: NMRIFoxn $\left.1^{n u} / F_{0 x n} 1^{n u}\right)$ were purchased from a professional breeder (Janvier Labs, Saint-Berthevin, France) at 4 weeks of age. Mice were placed in cages as groups of five in HEPAfiltered closets with water and food ad libitum, and were quarantined for a minimum of 10 days prior to surgery. Once under general anesthesia by inhalation of isoflurane, the skin was disinfected with $1 \%$ iodine alcoholic solution. For subcutaneous implants, BCP granules alone (BCP) or in association with BMSCs (BCP + BMSCs) were implanted on the dorsal side in two subcutis pockets that were created by skin incisions and tissue dilacerations with sterile 
instruments. Then $20 \times 10^{6}$ BMSCs (passage 1) with $1 \mathrm{~cm}^{3}$ BCP were implanted per subcutaneous site in randomly assigned nude mice. BMSCs from five donors that were transported were implanted subcutaneously: Donor $1, n=6$; Donor 2, $n=6$; Donor 3, $n=4$; Donor 4, $n=8$; and Donor 5, $n=7$.

For calvaria implants, the mouse was maintained on a stereostatic frame and a skin incision of $1 \mathrm{~cm}$ was made to expose the skull. A critical-sized defect $4 \mathrm{~mm}$ in diameter was created in the calvaria bone [26] using a trephine and a dental micromotor (Nouvag NM3000; NOUVAG, Goldach, Switzerland). Constant saline irrigation was used during drilling. Then $3 \times 10^{6}$ BMSCs in passage 2 or 3 were seeded onto one side of a BCP disc 1 hour prior to implantation. Cells from three different human donors were used. Discs were overlain cell-side down over the calvaria defect. Calvaria defects overlain with BCP discs alone or defects that were left empty served as controls. Skin incisions were closed with sutures (Filapeau; Peters Surgical, Bobigny, Ile-de-France, France). Analgesic $(20 \mu \mathrm{g} / \mathrm{kg}$; Buprenorphine, Axience, France) was injected intramuscularly before surgery and every 8 hours for 3 days after surgery. Animals were observed daily and body weights were determined weekly. After 4 or 8 weeks, the mice were euthanized by inhalation of an overdose of carbon dioxide gas. Sample sizes for calvaria implantations were as follows: 4 weeks empty, $n=3$; 4 weeks BCP, $n=3$; 4 weeks BCP + BMSCs, $n=4 ; 8$ weeks empty, $n=3 ; 8$ weeks BCP, $n=6$; and 8 weeks BCP + BMSCs, $n=5$.

\section{Decalcified histology preparation, staining and histomorphometry}

Explants were observed for signs of tissue necrosis, inflammation or infection, dissected and fixed in 10 volumes of buffered $4 \%$ formaldehyde for 72 hours. The skulls were further dissected using a diamond saw. Explants were decalcified in $4.13 \%$ ethylenediamine tetraacetic acid/0.2\% paraformaldehyde in phosphate-buffered saline, $\mathrm{pH} 7.4$ for 96 hours at $50^{\circ} \mathrm{C}$ using an automated microwave decalcifying apparatus (KOS Histostation; Milestone Medical, Kalamazoo, Michigan, USA). Samples were then dehydrated in ascending series of ethanol baths (80, 95 and $100 \%)$ and finally in butanol for 30 minutes in an automated dehydration station (Microm Microtech, Lyon, France). Samples were then impregnated in liquid paraffin at $56^{\circ} \mathrm{C}$ (Histowax; Histolab, Gottenburg, Sweden) and embedded at $-16^{\circ} \mathrm{C}$. Blocks were cut using a standard microtome (Leica RM2255; Leica Biosystems, Nanterre, Ile-de-France, France). Thin histology sections (3 to $5 \mu \mathrm{m}$ thick) were made perpendicular to the plane of the skin for subcutis implants and in the middle of calvaria defects. Sections were stained by Masson trichrome technique using an automated coloration station (Microm Microtech). This staining combined hematoxylin for cell nuclei (blue/black), fuchsine for cytoplasm, muscle and erythrocytes (red), and light green solution for collagen (green). Stained slices were scanned (NanoZoomer; Hamamatsu, Photonics, Hamamatsu City, Shizuoka Prefecture, Japan) and observed with the virtual microscope (NDP view; Hamamatsu). Histomorphometry of images were processed on the whole implant sections using Image J software (National Institute of Health, Bethesda, Maryland, USA) and the percentage areas of biomaterial, bone tissue, and bone marrow per implant were calculated.

\section{Nondecalcified histology and backscattered scanning electron imaging}

Fixed explants were dehydrated in ascending graded ethanol series followed by one bath of pure acetone and then impregnated with methylmethacrylate for 4 days at $4^{\circ} \mathrm{C}$. Each resulting block was cut in half with a circular diamond saw (Leica SP1600) and polished with 4,000grit silicon carbide sandpaper. Samples were sputtered with a thin layer of gold-palladium (JEOL JFC - 1100E; JEOL, Akishima, Japan) and backscattered electron images were taken using a scanning electron microscope, operating at an accelerating voltage of $15 \mathrm{kV}$ (HITACHI TM-3000; HITACHI, Tokyo, Japan).

\section{In situ hybridization}

In situ hybridization using the human-specific repetitive Alu sequence, which comprises approximately $5 \%$ of the total human genome, was performed for identification of human cells as described previously [27] with minor changes. Analysis was performed on ectopic explants of $50 \mathrm{mg}$ BCP particles with or without $2 \times 10^{6}$ of passage 2 BMSCs. Briefly, sections were treated with $3 \%$ hydrogen peroxide for 15 minutes at room temperature, then with $10 \mu \mathrm{g} / \mathrm{ml}$ proteinase $\mathrm{K}$ (Sigma-Aldrich, Lyon, France) for 10 minutes at $37^{\circ} \mathrm{C}$, followed by $0.25 \%$ acetic acid in $0.1 \mathrm{M}$ triethanolamine, $\mathrm{pH} 8.0$ for 20 minutes at room temperature. Prehybridization was performed for 3 hours at $56^{\circ} \mathrm{C}$ in a hybridization buffer containing $4 \times \mathrm{SSC}$ (Sigma-Aldrich), 50\% deionized formamide, $1 \times$ Denhardt's solution, $5 \%$ dextran sulfate, $100 \mu \mathrm{g} / \mathrm{ml}$ salmon sperm DNA and molecular-grade water. Hybridization buffer was refreshed with the addition of $70 \mathrm{nM}$ custom DIG-labeled human locked nucleic acid Alu probe 5DigN/ 5'-TCTCGATCTCCTGACCTCATGA-3'/3DigN (Exiqon, Vedbaek, Denmark) and then target DNA and the probe were denatured for 5 minutes at $95^{\circ} \mathrm{C}$. Hybridization was carried out for 19 hours at $56^{\circ} \mathrm{C}$. The hybridized probe was detected by immunohistochemistry using biotin-SPconjugated IgG fraction monoclonal mouse anti-digoxin (Jackson Immunoresearch, West Grove, Pennsylvania, USA) diluted $1 / 200$ in Tris-buffered saline with Tween, $2 \%$ bovine serum albumin for 35 minutes at $37^{\circ} \mathrm{C}$. 
Stretoperoxidase was added (1/200 in Tris-buffered saline with Tween) for 45 minutes at $37^{\circ} \mathrm{C}$ before diaminobenzidine substrate addition (Dako, Les Ulis, Ile-de-France, France). Sections were counterstained with Gill-2 hematoxylin (Thermo Shandon Ltd, Runcorn, UK).

\section{Bioluminescence imaging of luciferase-expressing BMSCs} To monitor the biological activity of BMSCs implanted subcutaneously, BMSCs were genetically modified using lentiviral units to co-express luciferase and green fluorescent protein (eGFP) reporter genes as described previously [28]. Briefly, cells were amplified in alpha minimum essential medium supplemented with $8 \%$ human PL, $100 \mathrm{U} / \mathrm{ml}$ penicillin and $100 \mu \mathrm{g} / \mathrm{ml}$ streptomycin, $1 \mathrm{U} / \mathrm{ml}$ heparin and $1 \mathrm{ng} / \mathrm{ml}$ basic fibroblast growth factor. The percentage of luciferase and eGFP expressing cells (Luc/eGFP MSCs) was quantified by measuring the eGFP expression by flow cytometry (FC-500 Flow cytometer; Beckman Coulter, Nyon, Switzerland). Luciferase activity was measured for $1 \times 10^{5}$ cells in a 96-well plate with $100 \mu \mathrm{l}$ lysis substrate buffer (Steady-Glo Luciferase Assay; Promega, Charbonnieres-les Bains, France) and $100 \mu \mathrm{l}$ culture medium using a VICTOR plate reader (Perkin Elmer, Waltham, Massachusetts, USA). Cells in passage 8 were used for bioluminescence imaging (BLI) experiments. The experimental group consisted of $1 \times 10^{6}$ Luc/eGFP MSCs in unison with $25 \mathrm{mg}$ BCP implanted subcutaneously in nude mice $(n=6)$ as described above. A control group consisted of a subcutaneous injection of $1 \times 10^{6}$ Luc/eGFP MSCs on the right dorsal side of mice and $25 \mathrm{mg}$ BCP implanted alone on the left dorsal side $(n=6)$. Luciferase activity was monitored at days $0,2,4,8,11,14,18,21,28$ and 37 using a photon imager (Biospace, Paris, France). Before each acquisition, $3 \mathrm{mg}$ luciferin-D in $250 \mu \mathrm{l}$ distilled, sterile water was injected intraperitoneally. The BLI results are expressed as counts per minute.

\section{Statistical analysis}

All experiments were blinded and data are expressed as mean \pm standard error of the mean. Statistical comparison between groups was performed using a one-way analysis of variance. Minitab statistical software was used (Minitab 16; Minitab Ltd, Coventry, UK). Statistical significance was set as $P<0.05$.

\section{Results}

\section{Bone marrow stromal cell production and} characterization

Several batches of BMSCs were isolated from bone marrow and expanded in GMP conditions using PL as a fetal calf serum alternative. After only one passage several hundred million BMSCs were consistently produced, as reported previously [6]. The BM-MNC content was $10.47 \times 10^{6} \pm$ $4.43 \times 10^{6} / \mathrm{ml}$. The CFU-F content was $357 \pm 155 \mathrm{CFUs} / 10^{6}$
BM-MNCs. The CFU-F content in aspirates performed (about 3,738/ml bone marrow aspirate) is therefore well above the described range by Cuthbert and colleagues [29], confirming high-quality bone marrow aspirates were obtained. Furthermore, the doubling times of the BMSCs from each of the donors used for ectopic bone formation (Donors 1 to 5 ) and from the donors used for calvaria regeneration (Donors 6 to 8 ) are presented in Table 1. Phenotypic characterization of BMSCs by flow cytometry is presented in Figure 1a and showed that $>90 \%$ of BMSCs expressed surface markers CD73, CD90, CD105 and HLA A-B-C, and $<5 \%$ expressed surface markers CD3, CD34, CD45 and HLA DP,DQ,DR. Confirmation of the adipogenic, chondrogenic and osteogenic in vitro differentiation capacity of BMSCs is presented in Figure 1b.

\section{Optimal cell dosage for bone formation}

An initial objective of this study was to determine the number of cells required for bone formation. Different quantities of cells, in unison with BCP particles, were therefore implanted subcutaneously in nude mice. Bone and bone marrow were quantified after 8 weeks and presented as a percentage of the total implant crosssectional area. As illustrated in Figure 2, no bone formation was demonstrated in either the 0 or and $0.1 \times 10^{6}$ cell groups. Conversely, both the $2 \times 10^{6}(13.30 \pm 3.23)$ and $4 \times 10^{6}(16.54 \pm 3.33)$ cell groups formed significantly more bone compared with both the 0 and $0.1 \times$ $10^{6}$ cell groups $(P<0.02)$. There was no significant difference in the quantity of bone formed between the $2 \times 10^{6}$ and $4 \times 10^{6}$ cell groups. Bone marrow territories were present only in the $2 \times 10^{6}(0.51 \pm 0.47)$ and $4 \times 10^{6}$ $(0.97 \pm 0.77)$ cell groups, but the difference between groups did not reach statistical significance. Based on these results the optimal cell dosage was set at $2 \times 10^{6}$ cells/50 mg BCP. Since $1 \mathrm{~cm}^{3}$ BCP weighs $500 \mathrm{mg}$, this cell dosage translates to $20 \times 10^{6}$ cells $/ \mathrm{cm}^{3}$ biomaterial.

\section{Viability following transportation of clinical batches of fresh BMSCs}

The determined optimal cell dosage of $20 \times 10^{6}$ cells $/ \mathrm{cm}^{3}$ biomaterial translates to $100 \times 10^{6}$ BMSCs for filling clinically relevant sized bone defects of $5 \mathrm{~cm}^{3}$. Syringes containing $100 \times 10^{6}$ BMSCs were shipped from Germany within 24 hours and the cell viability was determined upon arrival in France. As presented in Figure 3, the average percentage cell viability upon arrival in syringes with 4\% HSA was $69.9 \pm 9.55 \%$, with $5 \%$ HSA was $69.15 \pm$ $5.43 \%$ and with $20 \%$ HSA was $87.27 \pm 5.26 \%$, with no statistical difference between transportation media. Syringes containing the BMSCs and biomaterial are shown in Figure 3a,b,c,d. A standard operating procedure was developed for mixing cells and biomaterial under aseptic condition in the surgical room for 1 hour. It was 
Table 1 Doubling times of bone marrow stromal cells used for bone formation assessment

\begin{tabular}{|c|c|c|c|c|c|c|c|c|}
\hline Donor & 1 & 2 & 3 & 4 & 5 & 6 & 7 & 8 \\
\hline Passage 0 doubling time (hours) & 20.8 & 21.5 & 20.4 & 21.8 & 20.2 & 27.0 & 27.8 & 26.4 \\
\hline Passage 1 doubling time (hours) & 48.4 & 35.1 & 39.7 & 33.1 & 34.8 & 39.6 & 60.2 & 39.3 \\
\hline Passage 0 number of population doublings & 12.1 & 11.2 & 11.7 & 10.9 & 11.7 & 12.4 & 12.1 & 12.6 \\
\hline Passage 1 number of population doublings & 2.4 & 3.3 & 3.0 & 3.5 & 3.3 & 4.2 & 2.8 & 4.2 \\
\hline Cumulative population doublings & 14.5 & 14.5 & 14.7 & 14.4 & 15.0 & 16.6 & 14.9 & 16.8 \\
\hline Protocol option as published by Fekete and colleagues [6] & 2 & 2 & 2 & 2 & 2 & 1 & 1 & 1 \\
\hline
\end{tabular}

Donors 1 to 5 , ectopic; Donors 6 to 8 , calvaria.

previously demonstrated that 45 to $50 \%$ of BMSCs suspended in HSA attached to BCP particles after 1 hour [17]. Although we found that the maximal cell attachment was attained at approximately 4 hours after seeding, a 1-hour attachment time was chosen for the preclinical and clinical trials because this time frame is appropriate in the surgical setting. As shown by methylene blue staining (Figure 3f), this procedure guaranteed adequate attachment and even distribution of BMSCs on the $\mathrm{BCP}$ granules prior to implantation. (a)
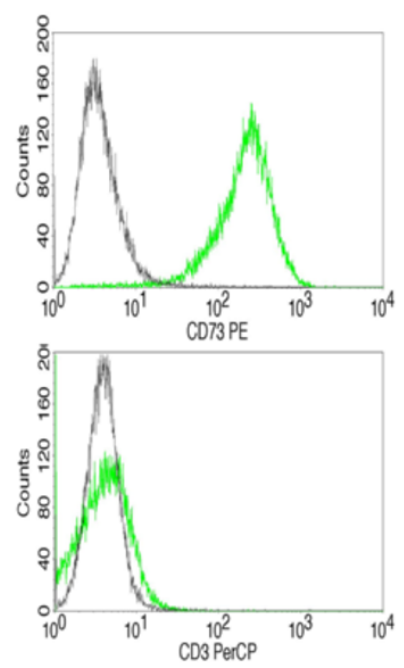
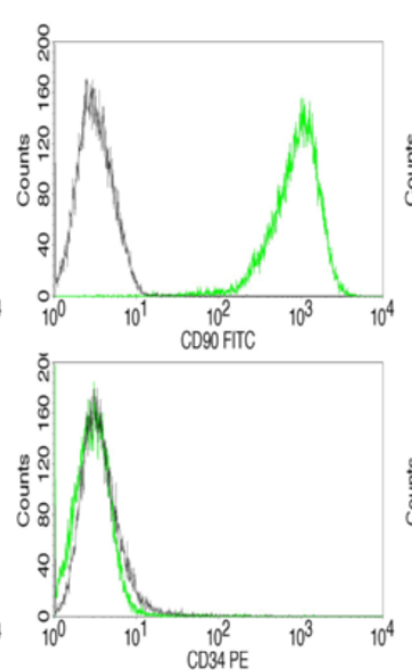
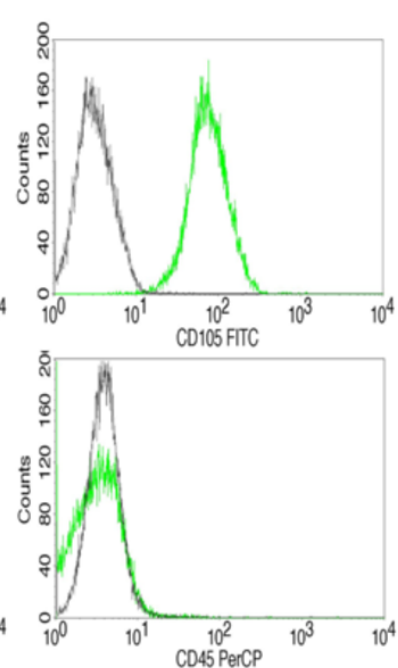
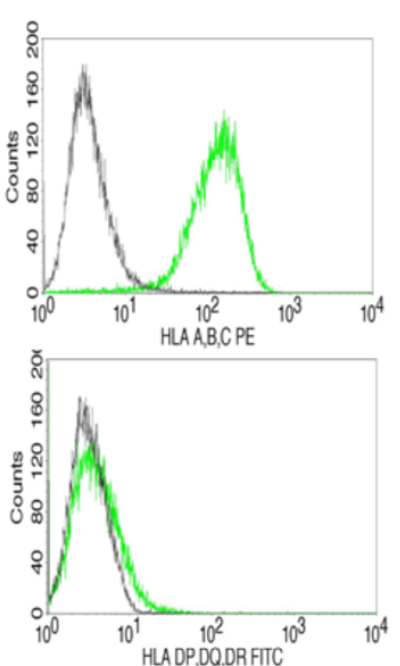

(b)

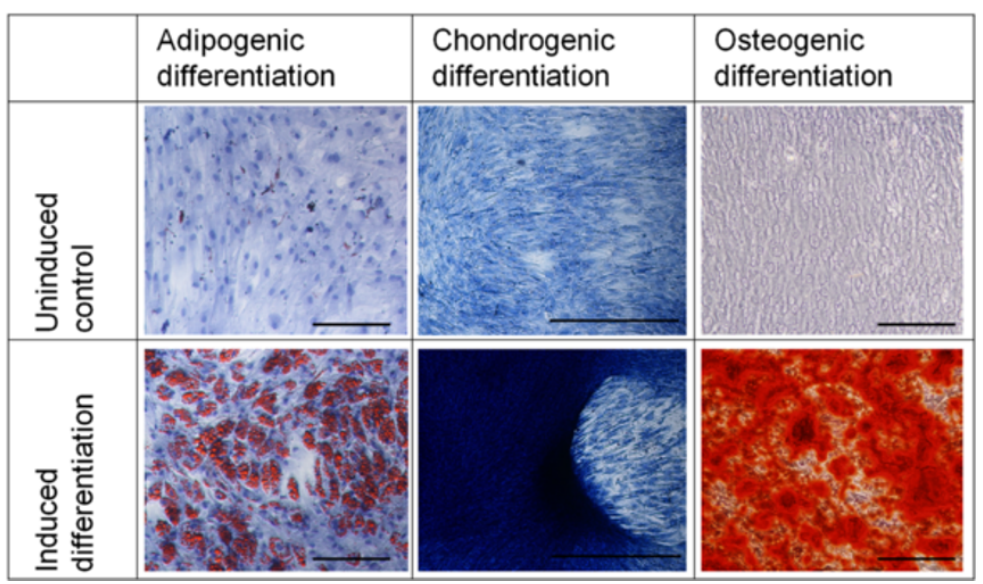

Figure 1 Characterization of bone marrow stromal cells. (a) Representative results of phenotypic characterization of good manufacturing practice-grade bone marrow stromal cells (BMSCs) by flow cytometry. More than 90\% of BMSCs express CD73, CD90, CD105 and HLA A-B-C, and $<5 \%$ of cells had surface antigen expression for CD3, CD34, CD45 and HLA DP, DQ, DR. (b) Tri-lineage differentiation capacity was confirmed. Adipogenic (Oil Red O/hematoxylin staining), chondrogenic (Alcian blue staining) and osteogenic differentiation (Alizarin red staining) could be induced, whereas no differentiation could be observed in controls without induced of differentiation. Black scale bars: $250 \mu \mathrm{m}$ for adipogenic, $500 \mu \mathrm{m}$ for osteogenic differentiation, and 1,000 $\mu \mathrm{m}$ for chondrogenic. 
(a)
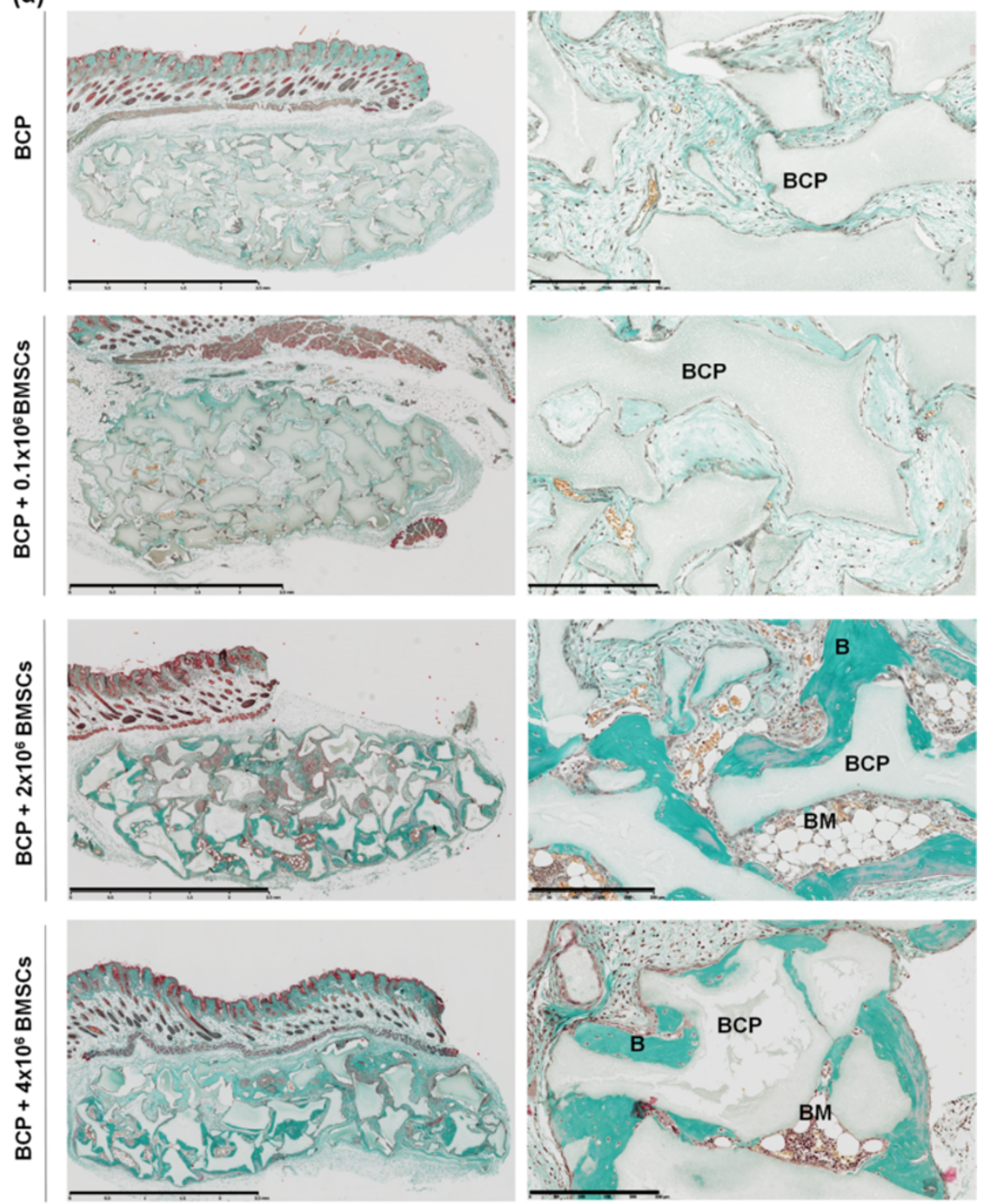

(b)

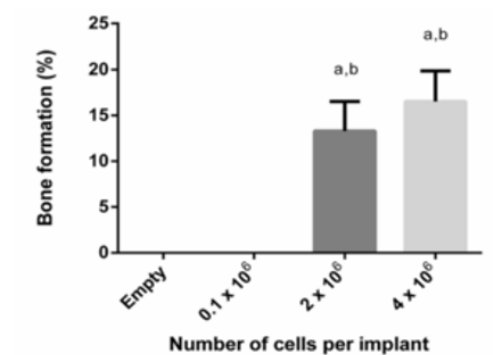

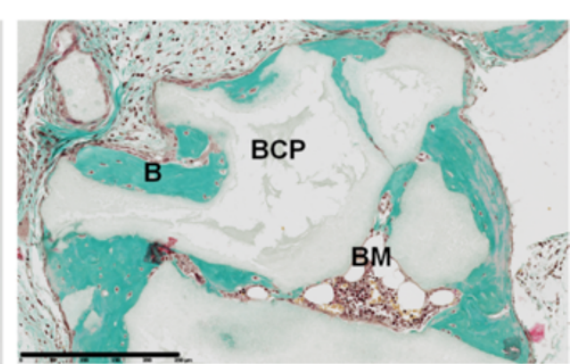

(c)

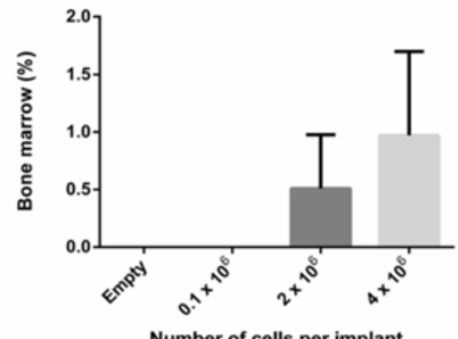

Figure 2 Optimal cell dosage for ectopic bone formation. (a) Masson trichrome staining shows biphasic calcium phosphate biomaterial $(B C P$, gray) in contact with newly formed bone ( $B$, green). Mature bone marrow territories (BM) were present after 8 weeks. Scale bars: $2.5 \mathrm{~mm}$ and $250 \mu \mathrm{m}$ for images in the left and right columns respectively. (b) Histomorphometry revealed significantly more bone in the $2 \times 10^{6}$ to $4 \times 10^{6}$ cell groups compared with the empty scaffolds $\left({ }^{(} P<0.02\right)$ and compared with the $0.1 \times 10^{6}$ cell group $\left({ }^{b} P<0.02\right)$. (c) Bone marrow territories were present only in the $2 \times 10^{6}$ and $4 \times 10^{6}$ cell groups, but there was no statistical difference between groups. BMSCs, bone marrow stromal cells. 

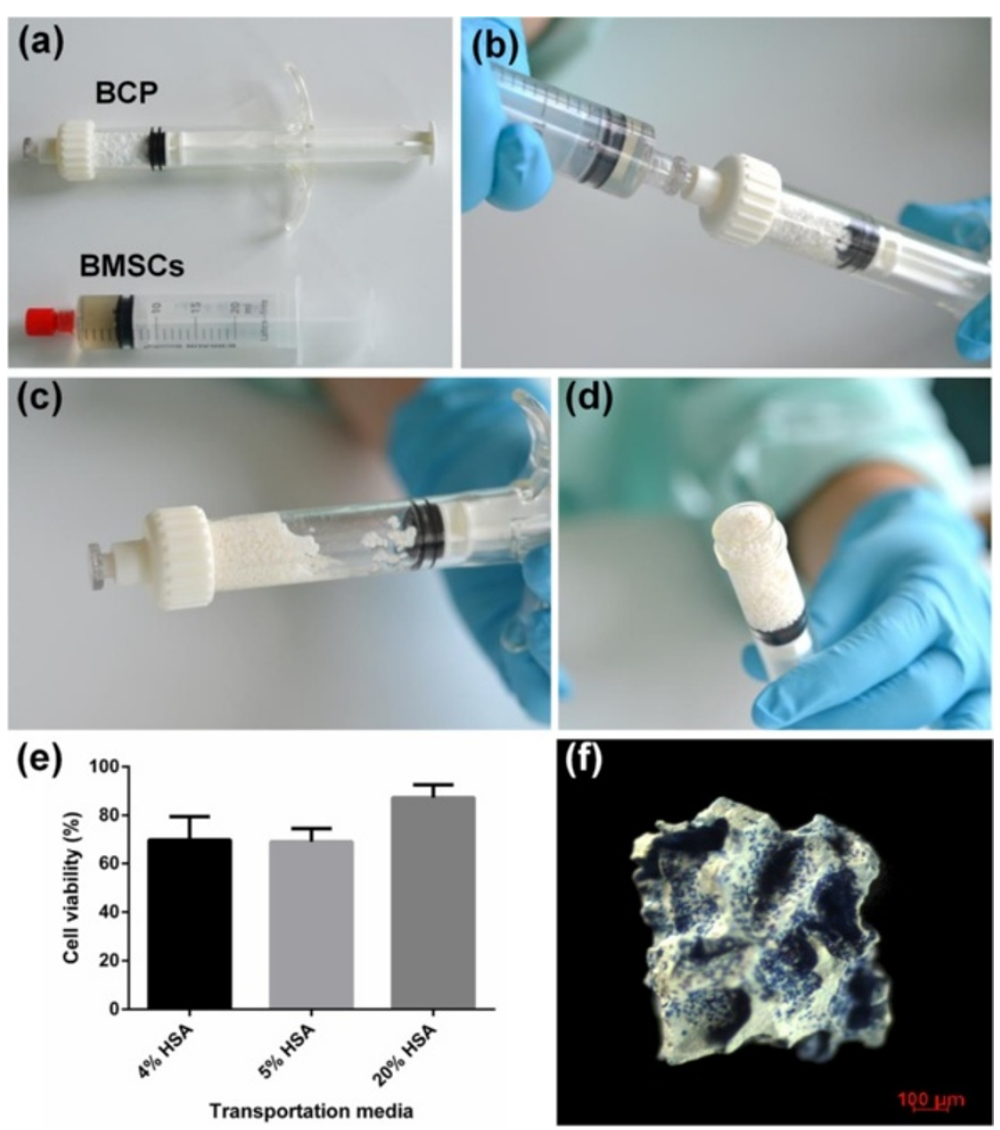

Figure 3 Transportation of fresh bone marrow stromal cells. (a) to (d) Syringes containing 100 million bone marrow stromal cells (BMSCs) were transported from Germany to France where they were mixed with biphasic calcium phosphate (BCP) biomaterial in sterile syringes. (e) No difference in viability of transported cells according to the percentage of human serum albumin (HSA) in the transportation media was found upon arrival in France. (f) Methylene blue staining shows cells attached to the BCP particles after 1 hour.

\section{Ectopic bone formation following transportation of several batches of BMSCs}

The ectopic model was performed to demonstrate the osteoinduction of the BMSC/BCP combination of seven GMP batches from five human donors that were transported fresh. The subcutis implantations in nude mice showed a thin fibrous tissue capsule with abundant vascularization without sign of tissue necrosis, local inflammation or infection. After 8 weeks, no ectopic bone formation was observed in control groups with $\mathrm{BCP}$ biomaterial alone (data not shown). In contrast, in the BCP + BMSCs group, ectopic bone formation was observed at the periphery of the explants and demonstrated a well-mineralized lamellar bone tissue with osteocyte lacunae, as illustrated by backscattered electron microscopy and Masson trichrome staining in Figure 4a,b,c. The percentage of bone formation revealed significant differences in the bone induction capacity between human donors, as presented in Figure 4d.

\section{Regeneration of critical size defects in calvaria of nude} mice

To investigate the potential of BMSCs to regenerate bone defects, BMSCs were implanted with BCP discs over critical-sized cranial defects. Defects that were either left empty or overlain with BCP biomaterial alone served as controls. All animals recovered well from surgery without signs of neurological damage. As shown in Figure 5a,b,c, no statistical difference in percentage of bone or bone marrow formation within the $\mathrm{BCP}$ discs was found between the $\mathrm{BCP}$ and $\mathrm{BCP}+\mathrm{BMSC}$ groups 4 weeks after implantation; however, a trend towards increased bone formation in the $\mathrm{BCP}+\mathrm{BMSCs}$ group was observed $(P<0.088)$. After 8 weeks, the percentage of bone formation was significantly higher in scaffolds with BMSCs $(37.41 \pm 8.93 \%)$ than BCP scaffolds alone $(1.58 \pm$ $0.51 \%)(P<0.02$; Figure $5 \mathrm{~b})$. Likewise, bone marrow presence was higher in the BCP + BMSCs group after 8 weeks $(5.56 \pm 1.95 \%)$ compared with the $\mathrm{BCP}$ group (no bone marrow presence) $(P<0.05$; Figure 5 c). Empty 

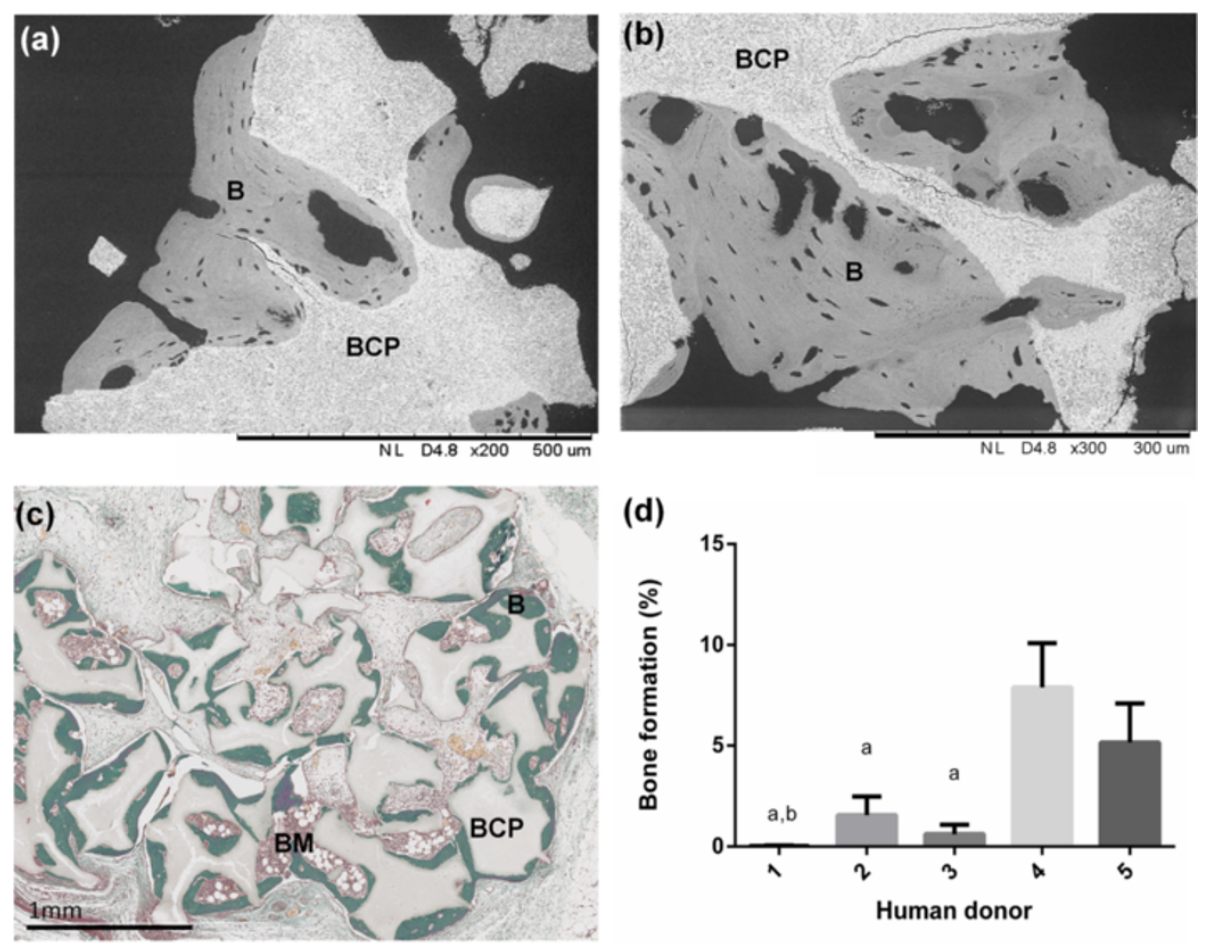

Figure 4 Ectopic bone formation of freshly transported batches of bone marrow stromal cells. (a), (b) In backscattered electron imaging, the biphasic calcium phosphate (BCP) ceramic and mineralized bone can be differentiated by their relative gray densities. The BCP particles were surrounded by a well-mineralized lamellar bone tissue in the BCP + BMSCs group after 8 weeks. (c) Masson trichrome staining showed bone formation (B) at the periphery of the explants that contained bone marrow compartments (BM). (d) Histomorphometry of Masson trichrome

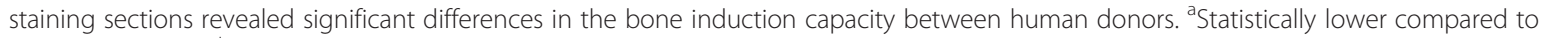
Donor $4(P<0.05)$. 'Statistically lower compared with to Donor $5(P<0.05)$. BMSCs, bone marrow stromal cells.

defects failed to achieve bone defect closure (percentage of defect closure was $26.29 \pm 14.29 \%$ after 4 weeks and $26.97 \pm 9.53 \%$ after 8 weeks) and were filled with fibrous tissue, confirming that the model was a criticalsized bone defect. Defect closure with BCP scaffolds alone was $35.75 \pm 5.08 \%$ after 4 weeks and $45.25 \pm$ $7.01 \%$ after 8 weeks. Some BCP + BMSCs samples achieved complete defect closure, as shown in Figure 5a. Most, however - especially those with significant bone formation within the biomaterial scaffold - did not achieve complete defect closure; rather, a bone bridging was accomplished by the bone-filled scaffold overlying the defect. Defect closure of BCP scaffolds with BMSCs was $40.50 \pm 11.01 \%$ after 4 weeks and $55.15 \pm 12.09 \%$ after 8 weeks; this was not statistically higher than the other groups however.

Bioluminescence imaging of luciferase-expressing BMSCs To assess the survival capacity and biological activity of BMSCs following implantation in vivo, BLI was performed on Luc/eGFP MSCs transplanted in nude mice. As depicted in Figure 6a,b, in the subcutaneous injection control group the BLI signal was $63,371.43 \pm 4,396.13$ at day 4, after which the signal dramatically decreased: at day 28 only $3 / 6$ mice had a detectable BLI signal (3.41 \pm $1.90)$ and no signal was present at day 37 . In the experimental group $(\mathrm{BCP}+\mathrm{BMSCs})$, the BLI signal also reduced throughout the duration of the experiment; however, it was a much less striking decline compared with the subcutaneous injection control group, as seen in Figure 6b. BCP particles dampen the BLI signal, as evidenced from Figure $6 b$, since the same quantity of cells was transplanted into both groups at day 0 but the BLI signal in the BCP + BMSCs group was significantly lower than that of the subcutaneous injection group $(5,184 \pm$ 622.96 vs. $84,082.61 \pm 10,478.04, P<0.05)$. Figure $6 c$ illustrates the percentage of the original signal at day 0 remaining at each time point. At day 8 there was a significantly higher percentage of initially transplanted cells remaining in the $\mathrm{BCP}+\mathrm{BMSCs}$ group, compared with the subcutaneous injection group (54.72 \pm 12.69 vs. 8.89 $\pm 3.78, P<0.01)$. This observation was corroborated at every later time point. By day $37,1.57 \pm 0.63 \%$ of the initial BLI signal remained in the BCP + BMSCs group, while there was no signal remaining in any of the subcutaneous injection mice. 
(a)
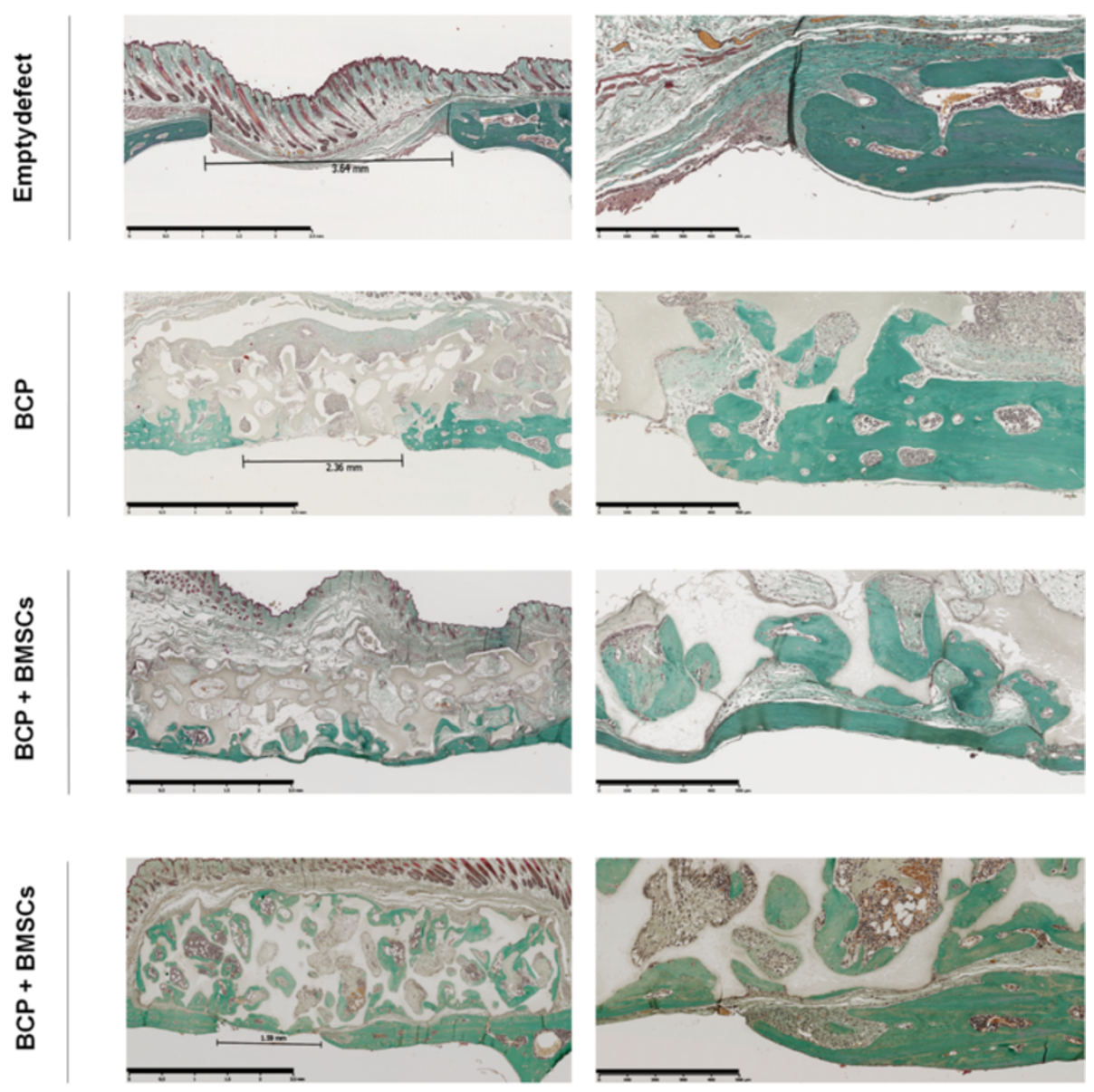

(b)

(c)
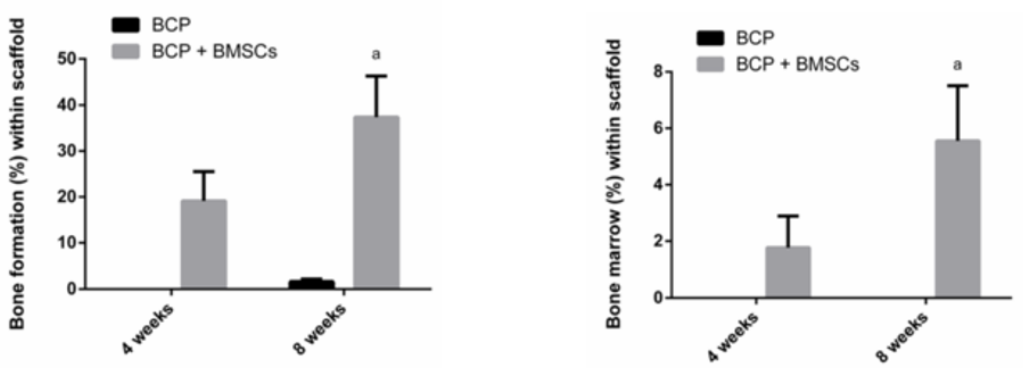

Figure 5 Regeneration of critical size defects in calvaria of nude mice. (a) Masson trichrome staining (MT) of calvaria defects after 8 weeks shows bone in green and biphasic calcium phosphate (BCP) in gray. Scale bars: $2.5 \mathrm{~mm}$ and $500 \mu \mathrm{m}$ for images in the left and right columns respectively. (b), (c) Histomorphometry of MT sections revealed that there was significantly more $\left({ }^{a} P<0.05\right)$ newly formed bone and bone marrow formed with the scaffolds of the BCP + BMSCs group compared with BCP discs without cells. BMSCs, bone marrow stromal cells.

\section{Identification of human cells by in situ hybridization}

In situ hybridization using the human-specific repetitive Alu sequence allowed for the identification of human cells in explants. As evidenced in Figure 7, after 8 weeks of implantation, it was observed that while most of the explants were comprised of host cells (purple nuclei), there were also human cells present (brown/black nuclei). Few human cells were present in the fibrous tissue, while more human cells were identified attached along the periphery of $\mathrm{BCP}$ particles. Furthermore, human osteocytes were found embedded in lacunae dispersed throughout the bone matrix with osteocytes of mice origin in close proximity. 


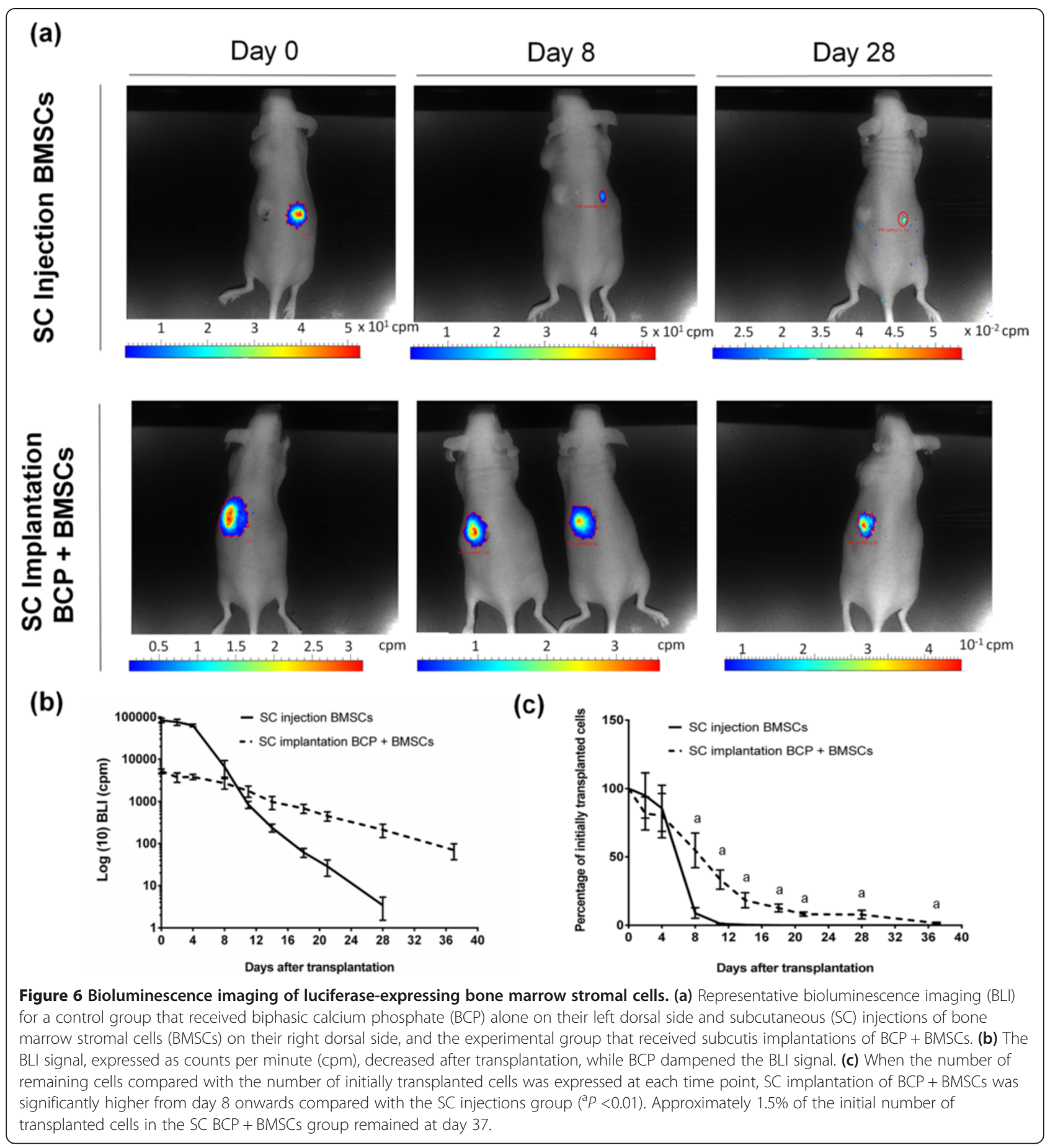

\section{Discussion}

Repair of bone defects remains a significant clinical challenge. In this study, 100 million BMSCs were transported in each syringe from a GMP facility in Germany to another site in France where they were mixed with biomaterial and implanted, mimicking the clinical scenario where large bone defects shall be regenerated. Bone containing mature bone marrow territories was formed in ectopic sites and in calvaria defects. Following implantation, the human cell number was drastically reduced; nevertheless, by 8 weeks some human cells were observed in osteocyte lacunae in newly formed bone.

It was important to investigate the optimal cell dosage for implantation in this study since, for clinical relevance, implanting too few cells would yield inadequate bone healing, while implanting more cells than required would result in cell wastage and more prolonged in vitro expansion times. A sharp increase in bone formation was found from 

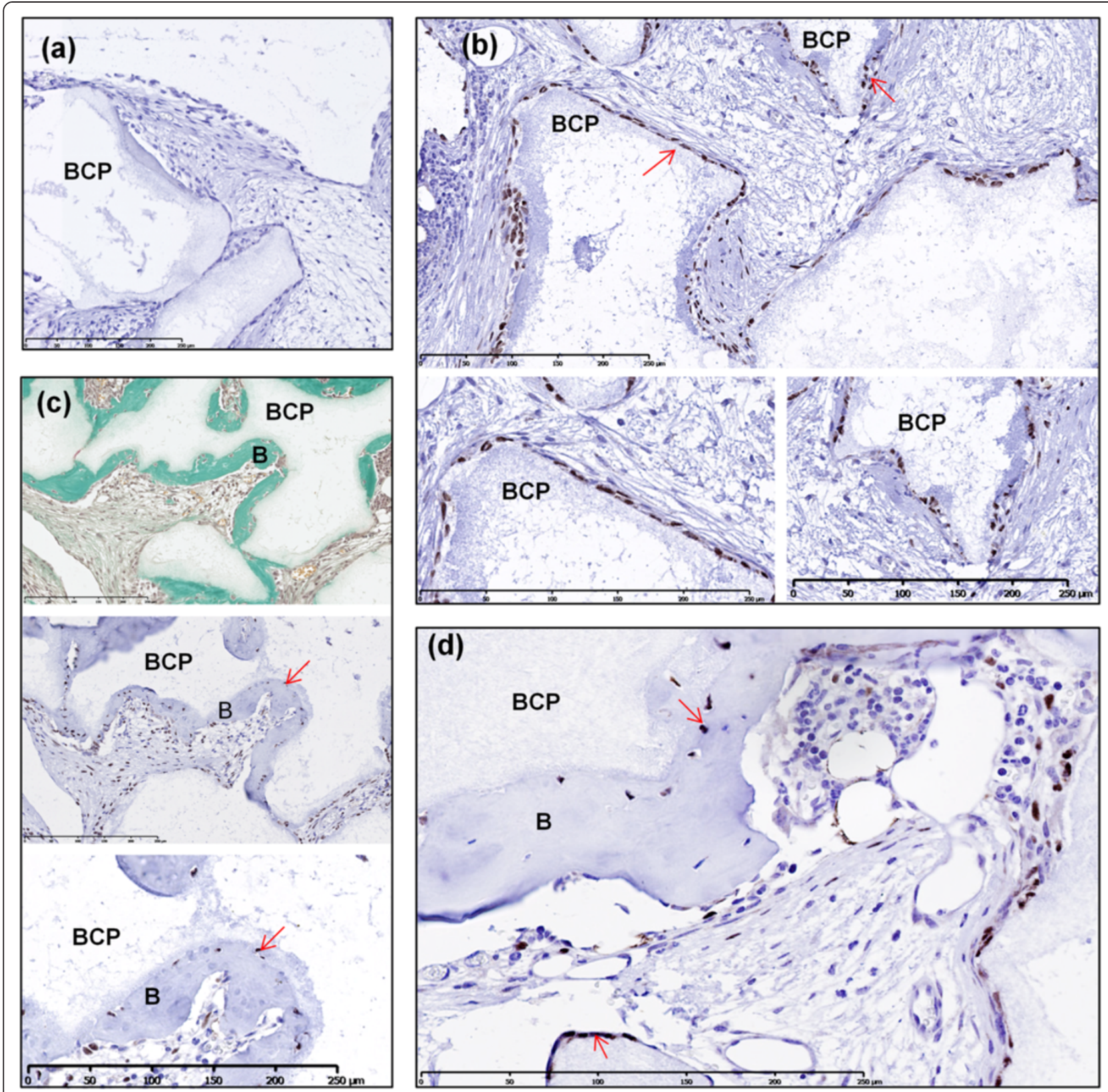

Figure 7 In situ hybridization using the human-specific repetitive Alu sequence for identification of human cells. All samples were analyzed after 8 weeks of subcutaneous implantation in nude mice (a) Negative control. (b) Although explants were composed primarily of mouse cells (purple nuclei), human cells (brown/black) were identified attached along the periphery of biphasic calcium phosphate (BCP) particles (red arrows). These regions of interest are shown in magnified view. (c) Masson trichrome staining of explants with a serial section showing human cells present (red arrow), with a magnified view also presented. (d) Explant showing mice cells (purple nuclei) and human cells (brown/black nuclei) embedded in osteocyte lacunae and surrounding BCP particles (red arrows). Scale bars: $250 \mu m$. B, bone formation.

$0.1 \times 10^{6}$ cells per implant to $2 \times 10^{6}$ cells per implant. Interestingly, doubling the cell density to $4 \times 10^{6}$ cells did not yield significantly more bone or bone marrow territories, demonstrating that a threshold was reached beyond which more implanted cells did not yield more bone formation. This result is in agreement with a previous study [12]. The ratio of cells to weight of biomaterial was then scaled up to a clinically equivalent dosage of $100 \times 10^{6}$
BMSCs per $5 \mathrm{~cm}^{3}$ of BCP granules. A standard operating procedure for mixing cells and biomaterial before implantation was developed. Bone formation was evaluated at 8 weeks since it has been shown previously that there is only minimal bone formation prior to this duration [12].

The percentage of HSA in the transportation media was reduced from $20 \%$ because it favored the formation of cell aggregates. The rationale for including both $4 \%$ and $5 \%$ 
HSA was because $4 \%$ HSA is commercially available in France whereas 5\% HSA is commercially available in Germany. Due to the large heterogeneity between human donors, it was not possible to assess whether the HSA concentration affected bone formation. However, independently of the percentage of HSA, the cell viability after transportation was approximately $70 \%$ and it is expected that this would be even higher in the clinical scenario due to the closer proximity of GMP production sites to the operating room. Cells attached to the BCP scaffold after only 1 hour and this is a clinically compatible preparation time for surgery of patients. Cells were transported at $20^{\circ} \mathrm{C}$ in this study; however, it must be noted that $4^{\circ} \mathrm{C}$ was since found to be a more optimal temperature [17].

Mature bone, including the presence of bone marrow territories, was observed after 8 weeks in subcutis explants. Hematopoiesis was only observed in explants with significant bone formation. This timing is well in agreement with other reports describing ectopic bone formation $[18,19]$. The transplants devoid of implanted BMSCs did not achieve any bone formation. Furthermore, this study demonstrated that human BMSCs could form bone and aid healing of critical-sized calvaria defects after 8 weeks. Abundant bone was formed within the BCP discs with mature bone marrow territories, which is relevant for maxillofacial regeneration.

The significant variability in the bone formation capacity between human donors is in agreement with previous studies [30,31]. Age, gender, disease and medications have been associated with altered prevalence of BMSCs in bone marrow as well as their activity in vitro [32-34]. In the current study, BMSCs were attained from healthy human donors ranging in age from 21 to 26, so age or disease was not a factor here. In addition, there was no correlation found between the bone formation capacity of the BMSCs from the five donors used for ectopic bone formation and the colony-forming efficiency of the bone marrow aspirates, expressed as CFUs-F/10 $\times 10^{6}$ MNCs (data not shown). Others found that there was no correlation between gender and bone formation capacity [30]. Understanding the underlying factors responsible for donor variability is of paramount importance for the clinical application of BMSCs for bone regeneration and will be the focus of future investigations.

In this study, the fate of the implanted cells in subcutaneous sites in the early and late stages of engraftment was evaluated using both bioluminescence imaging and in situ hybridization for the human-specific Alu sequence. We observed significant loss of the BLI signal over the experiment duration, with only approximately $1.5 \%$ of transplanted cells remaining after 37 days. It must be noted, however, that since the Luc/eGFP MSCs used for the bioluminescence imaging were in passage 8, this could have possibly contributed to their early disappearance due to higher doubling times that accompany high passage numbers. Nevertheless, this finding is in agreement with other studies noting a large loss of transplanted BMSCs $[24,25]$. Furthermore, although the BCP particles reduced the BLI signal intensity of BMSCs, the reliability of BLI for determining viable cell numbers was previously confirmed with BCP and BMSCs [24].

At 8 weeks, using in situ hybridization for the humanspecific Alu sequence (BMSCs implanted at passage 2), it was observed that there were some human cells found along the periphery of the BCP particles and embedded in osteocyte lacunae; however, the vast portion of cells present were of host origin. A previous study also found donor cells present in newly formed bone tissue [13]. However, in other studies no implanted BMSCs were observed in newly formed bone and host cells were directly responsible for bone formation $[23,35,36]$. There could be numerous reasons for these conflicting observations between studies, including the methods of ex vivo expansion (fetal calf serum vs. PL), the type of scaffold used (some scaffolds are better than others at retaining BMSCs), and even the strain of recipient mice (how immune deficient they are). The primary factors responsible for the large cell death of transplanted BMSCs include the ischemic environment [25] and the lack of glucose that the BMSCs encounter [37]. Despite this substantial cell death, the transplanted BMSCs mediated bone formation by host BMSCs, suggesting that transplanted BMSC-secreted paracrine molecules may play an important role in bone formation by host BMSCs.

It has been shown previously that BMSC modulation of the foreign body reaction and interaction with the host immune cells play a role in BMSC-mediated bone formation [36]. Furthermore, we have recently demonstrated the role of BMSCs as mediators rather than effectors of bone formation by impacting the foreign body reaction [38]. BMSCs attracted circulating hematopoietic stem cells and prompted their differentiation into macrophages M1 and osteoclasts; ablation of osteoclastogenesis largely inhibited BMSC-mediated bone formation [38]. However, at present, the precise mechanisms of how donor BMSCs recruit host BMSCs to the site is uncertain and warrants further investigation.

In this study, BMSCs have been successfully expanded, transported and implanted for bone repair, mimicking a clinically relevant scenario. In unison with BCP biomaterial, BMSCs achieved ectopic bone formation with bone marrow territories and successfully repaired critical-sized cranial defects. A drastic loss of BMSC viability after transplantation was observed. Newly formed bone contained some cells of human origin, but explants were primarily composed of host cells. This study demonstrates the safety and efficacy of BMSC/BCP combinations for bone regeneration. 


\section{Conclusions}

Our findings provide therapeutic evidence that BMSC/ $\mathrm{BCP}$ associations may be used for bone regeneration and present crucial information for the implementation of human BMSC therapy in clinical practice for the treatment of nonunion fractures.

\section{Abbreviations \\ BCP: biphasic calcium phosphate; BLI: bioluminescence imaging; BM-MNC: bone marrow mononuclear cell; BMSC: bone marrow stromal cell; CFU-F: colony-forming unit; GFP: green fluorescent protein; GMP: good manufacturing practice; HSA: human serum albumin; PL: plate lysate.}

\section{Competing interests}

MTR and HS work for a nonprofit organization that is manufacturing platelet lysate. The remaining authors declare that they have no competing interests.

\section{Authors' contributions}

MAB performed project planning, data collection, analysis and interpretation, and drafted the manuscript. AR participated in project planning and carried out the in vivo experiments. JA conducted histology and staining and collected data. MTR participated in project planning, data collection, analysis and interpretation. HS participated in project planning, and data collection, analysis and interpretation. DH participated in manuscript writing and provided administrative support. VT participated in project planning, data analysis and interpretation and manuscript writing. PL designed and supervised the experiments, and performed data interpretation and manuscript writing. All authors read and approved the final manuscript.

\section{Acknowledgements}

This work was supported by grants from the 7th Framework Program of the European Commission: CASCADE (Cultivated Adult Stem Cells as Alternative for Damaged tissuE) (HEALTH-F5-2009-223236) and REBORNE (Regenerating BOne defects using New biomedical Engineering approaches) (HEALTH2009-1.4.2-241879). The authors appreciate the excellent technical assistance of G Baur, T Becker, S Chester, D Erz, and C Späth.

\section{Author details}

'INSERM, UMR957, Laboratory of the Pathophysiology of Bone Resorption, Faculty of Medicine, 1 Rue Gaston Veil, 44035, University of Nantes, Nantes, France. ${ }^{2}$ Institute for Clinical Tranfusion Medicine and Immunogenetics, German Red Cross Blood Donor Service, Ulm, Germany.

Received: 21 May 2014 Revised: 30 September 2014

Accepted: 30 September 2014 Published: 13 October 2014

\section{References}

1. Giannoudis PV, Dinopoulos H, Tsiridis E: Bone substitutes: an update. Injury 2005, 36:S20-S27.

2. Pittenger MF, Mackay AM, Beck SC, Jaiswal RK, Douglas R, Mosca JD, Moorman MA, Simonetti DW, Craig S, Marshak DR: Multilineage potential of adult human mesenchymal stem cells. Science 1999, 284:143-147.

3. Caplan Al: The mesengenic process. Clin Plast Surg 1994, 21:429-435.

4. European Commisson: Regulation (EC) No 1394/2007 of the European Parliament and of the Council of 13 November 2007 on advanced therapy medicinal products and amending directive 2001/83/ and Regulation (EC) No 726/2004. Off J Eur Union 2007, 50:121-137.

5. Fekete N, Gadelorge M, Fürst D, Maurer C, Dausend J, Fleury-Cappellesso S, Mailänder V, Lotfi R, Ignatius A, Sensebé L, Bourin P, Schrezenmeier H, Rojewski MT: Platelet lysate from whole blood-derived pooled platelet concentrates and apheresis-derived platelet concentrates for the isolation and expansion of human bone marrow mesenchymal stromal cells: production process, content and identification of active components. Cytotherapy 2012, 14:540-554

6. Fekete N, Rojewski MT, Fürst D, Kreja L, Ignatius A, Dausend J, Schrezenmeier H: GMP-compliant isolation and large-scale expansion of bone marrow-derived MSC. PLoS One 2012, 7:e43255.

7. Schallmoser K, Rohde E, Bartmann C, Obenauf AC, Reinisch A, Strunk D: Platelet-derived growth factors for GMP-compliant propagation of mesenchymal stromal cells. Biomed Mater Eng 2009, 19:271-276.
8. Schallmoser K, Rohde E, Reinisch A, Bartmann C, Thaler D, Drexler C, Obenauf AC, Lanzer G, Linkesch W, Strunk D: Rapid large-scale expansion of functional mesenchymal stem cells from unmanipulated bone marrow without animal serum. Tissue Eng Part C Methods 2008, 14:185-196.

9. Crespo-Diaz R, Behfar A, Butler GW, Padley DJ, Sarr MG, Bartunek J, Dietz AB, Terzic A: Platelet lysate consisting of a natural repair proteome supports human mesenchymal stem cell proliferation and chromosomal stability. Cell Transplant 2011, 20:797-811.

10. Chevallier N, Anagnostou F, Zilber S, Bodivit G, Maurin S, Barrault A, Bierling P, Hernigou P, Layrolle P, Rouard H: Osteoblastic differentiation of human mesenchymal stem cells with platelet lysate. Biomaterials 2010 31:270-278

11. Livingston TL, Gordon S, Archambault M, Kadiyala S, Mclntosh K, Smith A, Peter SJ: Mesenchymal stem cells combined with biphasic calcium phosphate ceramics promote bone regeneration. J Mater Sci Mater Med 2003, 14:211-218.

12. Mankani MH, Kuznetsov SA, Robey PG: Formation of hematopoietic territories and bone by transplanted human bone marrow stromal cells requires a critical cell density. Exp Hematol 2007, 35:995-1004.

13. Fang D, Seo B-M, Liu Y, Sonoyama W, Yamaza T, Zhang C, Wang S, Shi S: Transplantation of mesenchymal stem cells is an optimal approach for plastic surgery. Stem Cells 2007, 25:1021-1028.

14. Liu G, Shu C, Cui L, Liu W, Cao Y: Tissue-engineered bone formation with cryopreserved human bone marrow mesenchymal stem cells. Cryobiology 2008, 56:209-215.

15. François M, Copland IB, Yuan S, Romieu-Mourez R, Waller EK, Galipeau J: Cryopreserved mesenchymal stromal cells display impaired immunosuppressive properties as a result of heat-shock response and impaired interferon- $\gamma$ licensing. Cytotherapy 2012, 14:147-152.

16. Hunt CJ: Cryopreservation of human stem cells for clinical application: a review. Transfus Med Hemother 2011, 38:107-123.

17. Veronesi E, Murgia A, Caselli A, Grisendi G, Piccinno MS, Rasini V, Giordano R, Montemurro T, Bourin P, Sensebe L, Rojewski MT, Schrezenmeier H, Layrolle P, Ginebra MP, Panaitescu CB, Gomez-Barrena E, Catani F, Paolucci $P$, Burns JS, Dominici M: Transportation conditions for prompt use of ex vivo expanded and freshly harvested clinical-grade bone marrow mesenchymal stromal/stem cells for bone regeneration. Tissue Eng Part C Methods 2014, 20:239-251.

18. Mankani MH, Kuznetsov SA, Fowler B, Kingman A, Robey PG: In vivo bone formation by human bone marrow stromal cells: effect of carrier particle size and shape. Biotechnol Bioeng 2001, 72:96-107.

19. Arinzeh TL, Tran T, Mcalary J, Daculsi G: A comparative study of biphasic calcium phosphate ceramics for human mesenchymal stem-cell-induced bone formation. Biomaterials 2005, 26:3631-3638.

20. Bruder SP, Kurth AA, Shea M, Hayes WC, Jaiswal N, Kadiyala S: Bone regeneration by implantation of purified, culture-expanded human mesenchymal stem cells. J Orthop Res 1998, 16:155-162.

21. Muraglia A, Martin I, Cancedda R, Quarto R: A nude mouse model for human bone formation in unloaded conditions. Bone 1998, 22:131S-134S.

22. Mankani MH, Kuznetsov SA, Wolfe RM, Marshall GW, Robey PG: In vivo bone formation by human bone marrow stromal cells: reconstruction of the mouse calvarium and mandible. Stem Cells 2006, 24:2140-2149.

23. Tasso R, Augello A, Boccardo S, Salvi S, Caridà M, Postiglione F, Fais F, Truini M, Cancedda R, Pennesi G: Recruitment of a host's osteoprogenitor cells using exogenous mesenchymal stem cells seeded on porous ceramic. Tissue Eng Part A 2009, 15:2203-2212.

24. Giannoni P, Scaglione S, Daga A, llengo C, Cilli M, Quarto R: Short-time survival and engraftment of bone marrow stromal cells in an ectopic model of bone regeneration. Tissue Eng Part A 2010, 16:489-499.

25. Becquart $\mathrm{P}$, Cambon-Binder A, Monfoulet L-E, Bourguignon M, Vandamme $\mathrm{K}$, Bensidhoum M, Petite H, Logeart-Avramoglou D: Ischemia is the prime but not the only cause of human multipotent stromal cell death in tissue-engineered constructs in vivo. Tissue Eng Part A 2012, 18:2084-2094.

26. Krebsbach PH, Mankani MH, Satomura K, Kuznetsov SA, Robey PG: Repair of craniotomy defects using bone marrow stromal cells. Transplantation 1998, 66:1272-1278.

27. Steck E, Burkhardt M, Ehrlich H, Richter W: Discrimination between cells of murine and human origin in xenotransplants by species specific genomic in situ hybridization. Xenotransplantation 2010, 17:153-159.

28. Rousseau J, Escriou V, Perrot P, Picarda G, Charrier C, Scherman D, Heymann $D$, Rédini $F$, Trichet $V$ : Advantages of bioluminescence imaging to follow 
siRNA or chemotherapeutic treatments in osteosarcoma preclinical models. Cancer Gene Ther 2010, 17:387-397.

29. Cuthbert R, Boxall SA, Tan HB, Giannoudis PV, McGonagle D, Jones E: Single-platform quality control assay to quantify multipotential stromal cells in bone marrow aspirates prior to bulk manufacture or direct therapeutic use. Cytotherapy 2012, 14:431-440.

30. Janicki P, Boeuf S, Steck E, Egermann M, Kasten P, Richter W: Prediction of in vivo bone forming potency of bone marrow-derived human mesenchymal stem cells. Eur Cell Mater 2011, 21:488-507.

31. Wagner-Ecker M, Voltz P, Egermann M, Richter W: The collagen component of biological bone graft substitutes promotes ectopic bone formation by human mesenchymal stem cells. Acta Biomater 2013, 9:7298-7307.

32. Kučera T, Soukup T, Krs O, Urban K, Sponer P: Bone healing capacity in patients undergoing total hip arthroplasty. Acta Chir Orthop Traumatol Cech 2012, 79:52-58.

33. Muschler GF, Nitto H, Boehm CA, Easley KA: Age- and gender-related changes in the cellularity of human bone marrow and the prevalence of osteoblastic progenitors. J Orthop Res 2001, 19:117-125.

34. Stenderup K, Justesen J, Clausen C, Kassem M: Aging is associated with decreased maximal life span and accelerated senescence of bone marrow stromal cells. Bone 2003, 33:919-926.

35. Corre P, Merceron C, Vignes C, Sourice S, Masson M, Durand N, Espitalier F, Pilet P, Cordonnier T, Mercier J, Remy S, Anegon I, Weiss P, Guicheux J: Determining a clinically relevant strategy for bone tissue engineering: an 'All-in-One' study in nude mice. PLoS One 2013, 8:e81599.

36. Tour $G$, Wendel $M$, Tcacencu I: Bone marrow stromal cells enhance the osteogenic properties of hydroxyapatite scaffolds by modulating the foreign body reaction. J Tissue Eng Regen Med 2012, [Epub ahead of print].

37. Deschepper M, Manassero M, Oudina K, Paquet J, Monfoulet L-E, Bensidhoum M, Logeart-Avramoglou D, Petite H: Proangiogenic and prosurvival functions of glucose in human mesenchymal stem cells upon transplantation. Stem Cells 2013, 31:526-535.

38. Gamblin A-L, Brennan MA, Renaud A, Yagita H, Lézot F, Heymann D, Trichet $V$, Layrolle $P$ : Bone tissue formation with human mesenchymal stem cells and biphasic calcium phosphate ceramics: the local implication of osteoclasts and macrophages. Biomaterials 2014, 35:9660-9667.

doi: $10.1186 /$ scrt504

Cite this article as: Brennan et al.: Pre-clinical studies of bone regeneration with human bone marrow stromal cells and biphasic calcium phosphate. Stem Cell Research \& Therapy 2014 5:114.

\section{Submit your next manuscript to BioMed Central and take full advantage of:}

- Convenient online submission

- Thorough peer review

- No space constraints or color figure charges

- Immediate publication on acceptance

- Inclusion in PubMed, CAS, Scopus and Google Scholar

- Research which is freely available for redistribution 